\title{
Expression of microRNA in human retinal pigment epithelial cells following infection with Zaire ebolavirus
}

\author{
Genevieve F. Oliver ${ }^{1}$, Ayla V. Orang ${ }^{1}$, Binoy Appukuttan' ${ }^{1}$, Shashikanth Marri', Michael Z. Michael', \\ Glenn A. Marsh ${ }^{2}$ and Justine R. Smith ${ }^{1 *}$ (1)
}

\begin{abstract}
Objective: Survivors of Ebola virus disease (EVD) are at risk of developing blinding intraocular inflammation—or uveitis - which is associated with retinal pigment epithelial (RPE) scarring and persistence of live Zaire ebolavirus (EBOV) within the eye. As part of a large research project aimed at defining the human RPE cell response to being infected with EBOV, this work focused on the microRNAs (miRNAs) associated with the infection.

Results: Using RNA-sequencing, we detected 13 highly induced and 2 highly repressed human miRNAs in human ARPE-19 RPE cells infected with EBOV, including hsa-miR-1307-5p, hsa-miR-29b-3p and hsa-miR-33a-5p (up-regulated), and hsa-miR-3074-3p and hsa-miR-27b-5p (down-regulated). EBOV-miR-1-5p was also found in infected RPE cells. Through computational identification of putative miRNA targets, we predicted a broad range of regulatory activities, including effects on innate and adaptive immune responses, cellular metabolism, cell cycle progression, apoptosis and autophagy. The most highly-connected molecule in the miR-target network was leucine-rich repeat kinase 2, which is involved in neuroinflammation and lysosomal processing. Our findings should stimulate new studies on the impact of miRNA changes in EBOV-infected RPE cells to further understanding of intraocular viral persistence and the pathogenesis of uveitis in EVD survivors.
\end{abstract}

Keywords: Ebola, Filovirus, microRNA, Retina, Retinal pigment epithelium, Uveitis, Zaire ebolavirus

\section{Introduction}

Survivors of Ebola virus disease (EVD) suffer long-term sequelae. Intraocular inflammation-termed uveitis-develops in $18-34 \%$ of survivors [1, 2], and $40 \%$ of affected persons become blind [3]. Live Zaire ebolavirus $(\mathrm{EBOV})$ has been isolated from intraocular fluid after resolution of the viremia [4], and retinal scars that indicate involvement of the retinal pigment epithelium are associated with uveitis [3]. Zaire ebolavirus may persist at immune-privileged sites, such as the eye, since local immune responses are attenuated to avoid tissue damage. We previously demonstrated that human retinal pigment

\footnotetext{
*Correspondence: justine.smith@flinders.edu.au

1 Flinders University College of Medicine and Public Health, Flinders Medical Centre Room 4E-431, Flinders Drive, Bedford Park, SA 5042, Australia

Full list of author information is available at the end of the article
}

epithelial (RPE) cells mount a type I interferon (IFN) anti-viral response and maintain immunomodulatory activity when infected with EBOV, and this cell population may be a reservoir for EBOV in the eye [5].

MicroRNAs (miRNAs) are short (18-22 nt) fragments of single-stranded RNA that bind the $3^{\prime}$ untranslated region of mRNA, and directly suppress or indirectly activate gene expression. Because only a small (7-8 nt) "seed region" requires complementarity to permit binding, a single miRNA may have hundreds of mRNA targets, and thus play a complex regulatory role in cellular activity that varies by cell type and disease state [6]. We used small RNA sequencing (RNA-Seq) to identify miRNA expression in EBOV-infected human RPE cells, and conducted in silico analyses to identify biological targets of, and molecular interactions with, these miRNAs.

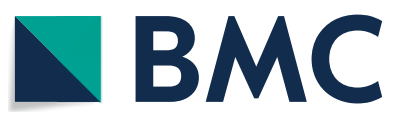

C The Author(s) 2019. This article is distributed under the terms of the Creative Commons Attribution 4.0 International License (http://creativecommons.org/licenses/by/4.0/), which permits unrestricted use, distribution, and reproduction in any medium, provided you give appropriate credit to the original author(s) and the source, provide a link to the Creative Commons license, and indicate if changes were made. The Creative Commons Public Domain Dedication waiver (http://creativecommons.org/ publicdomain/zero/1.0/) applies to the data made available in this article, unless otherwise stated. 


\section{Main text \\ Methods}

Total RNA was sourced from our previous study [5], in which the human RPE cell line (ARPE-19) [7] was infected in triplicate with EBOV (multiplicity of infection, 5) or mock-infected for $24 \mathrm{~h}$. From $1 \mu \mathrm{g}$ of RNA extract, small RNA was selectively enriched through sequential adapter ligation to $3^{\prime}$ and $5^{\prime}$ ends of RNA fragments using the TruSeq Small RNA Library Preparation Kit (Illumina, San Diego, CA). Single-stranded cDNA was synthesized by reverse transcription, and separately amplified with polymerase chain reaction using one of 48 primers containing index sequences ( 11 cycles). Using the Pippin Prep DNA Size Selection System (Sage Science, Beverley, MA), amplified cDNA constructs were purified from $3 \%$ agarose gel to isolate a library of small clone fragments. The library was sequenced on Illumina NextSeq 500, using NextSeq 75-cycle High Output Kits (Illumina), with the PhiX Control v3 library (Illumina) as sequencing control.

Short reads were filtered for adapters and reads of low quality using Cutadapt (v.1.8) [8] with error rate of 0.2 and minimum length of $18 \mathrm{bp}$, aligned against GENCODE human genome reference assembly GRCh38. p3 using Burrows Wheeler Aligner [9], and assigned to miRBase (v.21) annotations using HTSeq (v.0.6.1p2) $[10,11]$. Data were filtered for targets with a minimum of 10 counts in at least $50 \%$ of samples. After normalization, differentially expressed miRNAs between EBOVand mock-infected ARPE-19 cells were identified using the DESeq 2 statistical package (v.3.2) [12]. Reads were screened for complete matches to published EBOV miRNA sequences, allowing for 3 mismatches [13]. Raw data from our RNA-Seq study of the total RNA transcriptome of EBOV-infected ARPE-19 cells [5] (https:// www.ncbi.nlm.nih.gov/geo/query/acc.cgi?acc $=$ GSE10 0839) were processed in the same statistical pipeline used for human miRNAs, to identify genes that were differentially regulated with adjusted $\mathrm{p}$-value $\leq 0.05$ and $\log 2$ fold-change $\geq 1$.

Computational predictions of the targets of differentially expressed human miRNAs (defined by adjusted p-value $<0.001$ and $\log 2$ fold-change $>1$ ) were performed using public databases with different algorithms: Diana microT CDS (v.5.0) [14, 15], filtering with a threshold of 0.95; TargetScan (v.7.1) [16], sorting on a total context score $<0.15$; and miRDB (v.5.0) [17], with a target threshold $>85$. The human miRNAs were also input into public online repositories of experimentally-validated data on molecular interactions: miRecords (release 2013) and miRTarBase (v.7.0) [18, 19], set to 'strong evidence'.

Gene ontology [20] and pathway analyses were performed using Cytoscape (v.3.4.0) and ClueGO (v.2.3.3) plugin [21, 22], to identify enriched biological processes and molecular functions, and Kyoto Encyclopedia of Genes and Genomes (KEGG) pathways [23]. Using the STRING Action dataset (v.9) within CluePedia plugin (v.1.3.3) [24, 25] and collating miRNA-gene pairs, a miRNA-based network was constructed from miRNApredicted gene target lists, miRNA-validated target gene lists, and the differentially expressed gene list; interactions were demonstrated based on degree, to identify the most highly-connected genes and miRNAs. An inverse correlation was required between expression of an miRNA and its target gene in these analyses.

\section{Results}

RNA sequencing yielded $1.61-2.87 \times 10^{7}$ reads per replicate (Additional file 1). Filtering for size, 91-97\% of trimmed sequences were mapped to the human genome. 814 human miRNAs were identified (Additional file 2), and multidimensional scaling showed separation between results for EBOV- and mock-infected human RPE cells (Additional file 3). Defining differential expression as adjusted p-value $<0.05,28$ and 61 miRNAs were significantly increased and decreased, respectively, in EBOV-infected cells. Filtering stringently for adjusted p-value $<0.001$ and $\log 2$ fold-change $>1,13$ and $2 \mathrm{miR}$ NAs were significantly increased and decreased (Table 1 ). EBOV-miR-1-5p, EBOV-miR-T1-3p, EBOV-miR-T1-5p and EBOV-miR-T3-5p/T4-5p were identified in the infected human RPE cells (Additional file 4).

Putative target genes in EBOV-infected human RPE cells were predicted from the 15 highly differentially

\section{Table 1 List of miRNAs that were differentially expressed between EBOV- and mock-infected human RPE cells at $24 \mathrm{~h}$ post-infection}

\begin{tabular}{lcl}
\hline miRNA & log2 fold-change & Adjusted p-value \\
\hline hsa-miR-3074-3p & -1.52 & $1.24 \times 10^{-12}$ \\
hsa-miR-27b-5p & -1.06 & $2.63 \times 10^{-13}$ \\
hsa-miR-101-5p & 1.03 & $3.09 \times 10^{-8}$ \\
hsa-miR-33b-5p & 1.04 & $8.18 \times 10^{-5}$ \\
hsa-miR-190a-3p & 1.06 & $6.30 \times 10^{-5}$ \\
hsa-miR-1305 & 1.10 & $3.92 \times 10^{-6}$ \\
hsa-miR-130a-5p & 1.19 & $3.15 \times 10^{-5}$ \\
hsa-miR-32-5p & 1.21 & $2.39 \times 10^{-6}$ \\
hsa-miR-365a-5p & 1.24 & $2.39 \times 10^{-6}$ \\
hsa-miR-100-3p & 1.27 & $1.19 \times 10^{-13}$ \\
hsa-miR-33b-3p & 1.33 & $7.05 \times 10^{-10}$ \\
hsa-miR-4521 & 1.37 & $2.63 \mathrm{E}-13$ \\
hsa-miR-33a-5p & 1.41 & $5.10 \mathrm{E}-04$ \\
hsa-miR-29b-3p & 1.47 & $2.24 \mathrm{E}-08$ \\
hsa-miR-1307-5p & 1.50 & $1.98 \mathrm{E}-10$ \\
\hline
\end{tabular}


expressed miRNAs using algorithms: 2629 targets by Diana microT; 1799 targets by miRDB; and 14,315 targets by TargetScan (Additional file 5). Targets were also identified through interrogation of experimentally validated data: 44 targets by miRecords; and 9 targets by miRTarBase (Additional file 6). 1440 genes were differentially expressed between EBOV- and mock-infected ARPE-19 cells (Additional file 7). Highly enriched gene ontology categories and KEGG pathways were established for the target genes, based on numbers represented within categories and pathways, and ranking of corrected p-values (Fig. 1a-c, Additional file 8). The molecular network constructed from miRNA-target gene interactions included 363 highly connected molecules; most connected molecule was leucine-rich repeat kinase 2 (LRRK2), and most connected miRNA was hsa-miR-190a (Fig. 1d, Table 2, Additional files 9 and 10).

\section{Discussion}

Zaire ebolavirus causes uveitis in EVD survivors [26, 27]. We have identified miRNAs produced in human RPE cells following infection with EBOV. Viruses take advantage of host miRNAs to adjust gene expression and create an environment that supports replication [28]. Human RPE cells make multiple molecular adjustments in response to infection with EBOV [5], and miR-190a is central to the cell response. This highly connected miRNA contributes to cell survival and latency in Epstein-Barr virus (EBV) infection, by downregulating expression of tumor protein P53 inducible nuclear protein 1 and nuclear receptor subfamily 4 group A member 3 , thereby preventing cell cycle arrest and inhibiting apoptosis [29]. The same mechanism may be utilized by EBOV to promote viral replication in infected RPE cells. One other interacting miRNA-miR-101-prevents cell death in the context of herpes simplex virus type 1 infection [30], pointing to a common strategy among viruses to promote survival of both the virus and its host cell.

Another highly connected miRNA was miR-29b3p, which suppresses key immunological pathways by downregulating nuclear factor kappa-light-chain-enhancer of activated B cells (NF-kB) [31]. This transcription factor plays an essential role in the anti-viral type IFN response. Multiple receptors-including toll-like receptors and retinoic acid-inducible gene (RIG)-I-stimulate NF- $\kappa B$, which activates transcription of IFN $-\beta$ and
IFN-stimulated genes. Zaire ebolavirus profoundly inhibits the type I IFN response in monocytes and other cell populations, through the action of viral proteins-VP24 and VP35-and suppression of RIG-I signaling [32]. Our prior work has demonstrated that EBOV-infected RPE cells mount a type I IFN response [5]; however, EBOV also may suppress this pathway through activation of miR-29b-3p. Other viruses act similarly: the NF- $k B$ pathway is not activated in human RPE cells infected with cytomegalovirus [33]. MicroRNA-29b is also activated in Japanese encephalitis virus infection, particularly in persons with neurological sequelae, and elevated serum levels may indicate severe disease [34].

After entering the host cell, EBOV is transported via endolysosomal trafficking [35]. Infected cells also release exosomes containing EBOV VP40, which may promote leukocyte apoptosis [36]. Consistent with involvement of the endolysosomal system, the most highly connected molecule in the miRNA-target gene network was LRRK2. This protein is a key regulator of the system; a range of mutations in LRRK2 result in formation of large, dysfunctional lysosomes [37]. Interestingly, LRRK2 activation in microglia has been implicated in the progression of central nervous system inflammation, as occurs in Parkinson's disease and HIV-associated neurocognitive disorders [38]. This suggests LRRK2 activity in EBOVinfected RPE cells may contribute to the development of uveitis.

As applies to all viruses, EBOV infection involves hijacking translational machinery of the host cell to produce viral particles. Gene ontology enrichment analysis for molecular function showed strong activation of DNAbinding and transcription pathways in EBOV-infected human RPE cells. Known to bind double-stranded RNA, multiple genes in the $2^{\prime}-5^{\prime}$-oligoadenylate synthetase pathway were upregulated in our gene ontology enrichment analyses, indicating a miRNA-facilitated host response to EBOV. Activation of kinases was prominent; pathways involving kinases-such as protein kinase $\mathrm{R}$ are directly involved in the response to EBOV, binding to double-stranded RNA, activating cellular targets and inhibiting the host translational machinery [39].

Virus-infected cells release exosomes containing host- and virus-derived miRNAs that modulate gene expression in uninfected neighbouring cells [40]. Human RPE cells have the capacity to secrete exosomes

(See figure on next page.)

Fig. 1 a-c Graphs showing enriched gene ontology categories: a biological process, $\mathbf{b}$ molecular function and $\mathbf{c}$ KEGG pathways in human RPE cells $24 \mathrm{~h}$ post-infection with EBOV. Percentages indicate proportion of known genes represented within the grouping. $\mathbf{d}$ Network of interactions between protein-coding genes and miRNAs in EBOV-infected human RPE cells, with miRNAs indicated by yellow diamonds, molecules indicated by blue circles, and interactions that are promoting or inhibiting represented as blue or red lines, respectively. Size of circle or diamond is proportionate to the number of molecular interactions (or degrees). An enlarged version of $\mathbf{d}$ is presented as Additional file 8 
a

Sequence-specific double-stranded ONA binding

RNA polvmerase II regulatory resion sequence-specific ONA binding $=8.1 \%$

Core promoter proximal region sequence-specific ONA binding $\square 8.8 \%$

2'-5'-olligoadenylate synthetase activity $100 \%$

Transcriptional activator activity, RNA polymerase II sequence-specific binding $\square 9.4 \%$

Ubiquitin-like protein lizase binding $-\square .6 \%$

Transmembrane receptor protein tyrosine kinase activity $19.9 \%$

Growth factor receptor binding $12.7 \%$

Crookine binding $12.5 \%$

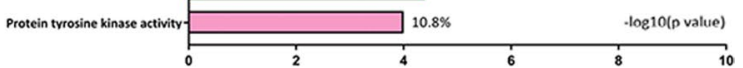

b

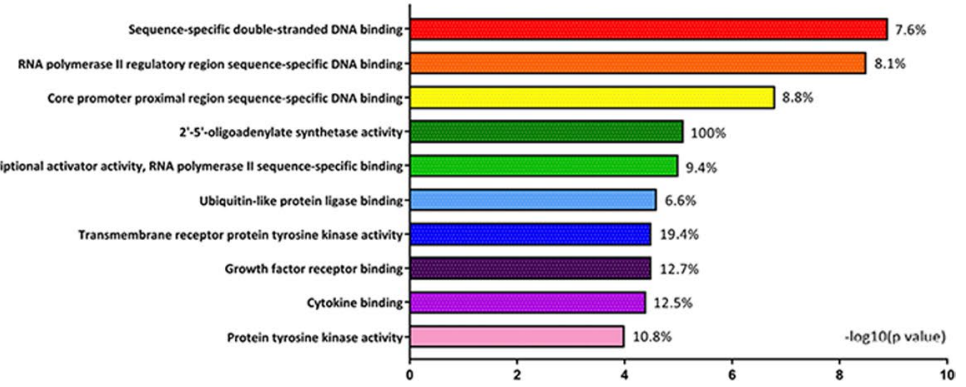

C

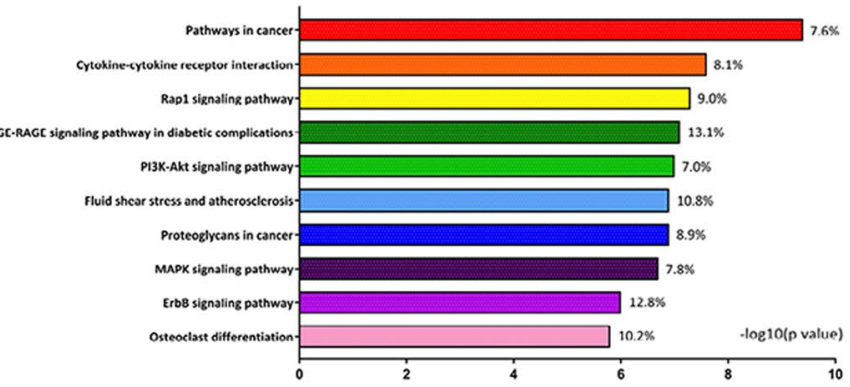

d

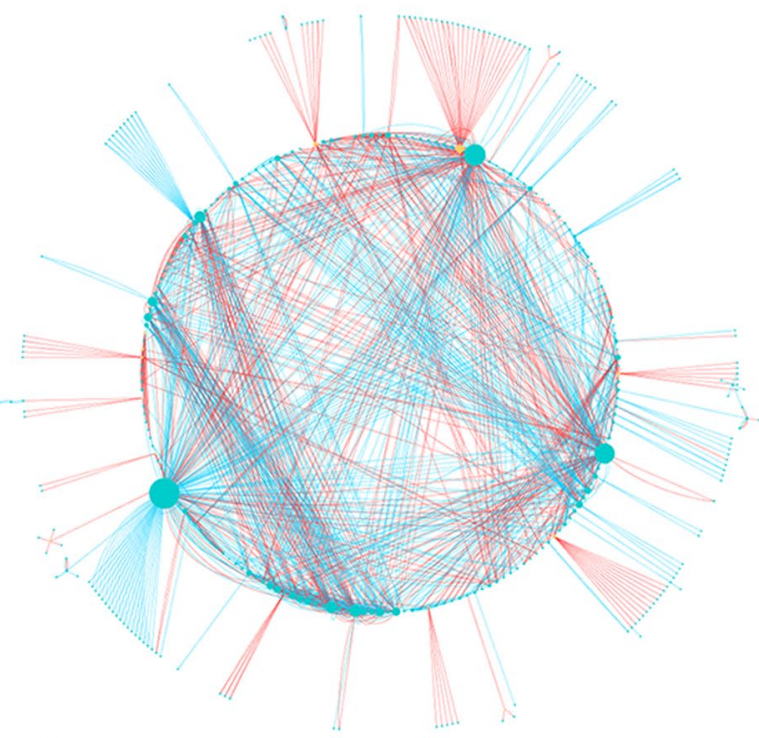


Table 2 List of highly-connected protein-coding genes (16 most connected) and miRNAs (all connected in EBOVinfected human RPE cells)

\begin{tabular}{|c|c|}
\hline Protein-coding genes & Degree \\
\hline LRRK2 & 181 \\
\hline MAPK13 & 125 \\
\hline MAPK7 & 117 \\
\hline PRKCE & 66 \\
\hline $\mathrm{PRKCH}$ & 64 \\
\hline SGK494 & 64 \\
\hline RND3 & 52 \\
\hline DIRAS3 & 44 \\
\hline RASD2 & 43 \\
\hline RASL11B & 43 \\
\hline PDGFRB & 37 \\
\hline ARHGEF3 & 36 \\
\hline IQGAP2 & 36 \\
\hline ARL14 & 35 \\
\hline ARL4A & 35 \\
\hline miRNA & Degree \\
\hline hsa-miR-190a & 58 \\
\hline hsa-miR-29b-3p & 25 \\
\hline hsa-miR-130a-5p & 17 \\
\hline hsa-miR-32-5p & 16 \\
\hline hsa-miR-33a-5p & 12 \\
\hline hsa-miR-33b-5p & 11 \\
\hline hsa-miR-7-5p & 11 \\
\hline hsa-miR-33b-3p & 7 \\
\hline hsa-miR-1305 & 6 \\
\hline hsa-miR-100-3p & 5 \\
\hline hsa-miR-19a-5p & 5 \\
\hline hsa-miR-101-5p & 4 \\
\hline hsa-miR-27b-5p & 3 \\
\hline hsa-miR-365a-5p & 1 \\
\hline hsa-miR-4521 & 1 \\
\hline
\end{tabular}

Degree indicates number of interactions for each molecule

containing miRNAs [41]. Our data indicate that hsamiR-27b-5p and hsa-miR-3074-3p are expressed at reduced levels when the cells become infected with EBOV, which might indicate active export of the miRNAs into exosomes. Both miRNAs are detected in the aqueous humour of healthy eyes, at levels higher than found in plasma indicating local production [42]. We speculate that levels of these miRNAs might be increased in the ocular fluid of EBOV survivors, particularly those with uveitis and present biomarkers for ocular involvement. Other investigators have identified a panel of 8 serum miRNAs that predict pre-symptomatic EBOV infection, facilitating an early diagnosis of EVD [43].
RNA viruses do not typically encode miRNAs [28]. However, our analysis of EBOV-infected RPE cells identified EBOV-miR-1-5p, which has been described by several investigator teams $[13,44]$. This ortholog of human miR-155 inhibits expression of importin- $\alpha 5$ and impacts type I IFN signaling [45]. Molecular mimicry of miR-155 is also seen in Kaposi sarcoma herpesvirus infection of B-cells, enabling the virus to drive the cell to a state that supports long-term latency and avoids apoptosis [46]. Several other EBOV-derived miRNAs were identified in the infected RPE cells, but with very low read counts suggesting negligible biological activity.

\section{Conclusion}

Our work provides new information about the potential post-transcriptional regulation of the human RPE cell response to infection with EBOV. Review of the biological targets of the 15 highly-induced or repressed miRNAs indicates a broad range of potential regulatory activities, including effects on immune responses, cellular metabolism, cell cycle progression, apoptosis and autophagy in the host cells. MicroRNA expression varies by tissue, including within the eye $[47,48]$; hence similar changes may not occur in other ocular tissues or tissues from other immune-privileged sites, such as testis. Future studies of the regulatory activities of these miRNAs in human RPE cells should delineate their involvement in the intraocular persistence of EBOV and EBOV-associated uveitis in EVD survivors.

\section{Limitations}

- We studied EBOV infection in the ARPE-19 human RPE cell line, in place of cells isolated from human eyes. This cell line is a well-characterized, robust model for studying human retinal pigment epithelium [5], and thus our findings should provide reasonable fidelity to an ocular infection in an EVD survivor.

- MicroRNA expression was evaluated at one timepoint post-infection. The time-point was selected in our previously published study [7], to be maximally informative of host cell responses to EBOV infection, and may be most applicable to EVD and early survivorship.

- Human RPE cells were studied in isolation, while the intraocular environment includes multiple cell populations. However, this approach allowed us to focus specifically on gene expression in a key intraocular target cell for EBOV. 
- Cells were infected with virulent EBOV, which caused recent EVD epidemics; less virulent Ebolavirus species may induce different miRNA expression. Cells were not co-infected with other pathogens: co-infection influences EVD outcome, which might in part reflect altered miRNA expression, as demonstrated in other infections $[49,50]$.

\section{Supplementary information}

Supplementary information accompanies this paper at https://doi. org/10.1186/s13104-019-4671-8.

Additional file 1. Trimming statistics for RNA sequencing data generated for small RNA expressed in human RPE cells at $24 \mathrm{~h}$ following infection with EBOV or mock-infection.

Additional file 2. Lists of total and differentially expressed host miRNAs expressed in human RPE cells at $24 \mathrm{~h}$ following infection with EBOV or mock-infection.

Additional file 3. Graphic showing multidimensional scaling of small RNA expressed in human RPE cell at $24 \mathrm{~h}$ post-infection with EBOV.

Additional file 4. List of EBOV miRNAs expressed in human RPE cells at $24 \mathrm{~h}$ following infection with EBOV or mock-infection.

Additional file 5. List of predicted miRNA targets from Diana microT, miRDB and TargetScan databases.

Additional file 6 . List of validated miRNA targets from miRecords and miRTarBase databases.

Additional file 7. List of differentially-expressed genes in human RPE cells at $24 \mathrm{~h}$ following infection with EBOV or mock-infection.

Additional file 8. List of enriched gene ontology categories (biological process, molecular function) and KEGG pathways for biological targets of differentially expressed miRNAs in EBOV-versus mock-infected human RPE cells.

Additional file 9. Results of network construction based around differentially expressed miRNAs in EBOV-versus mock-infected human RPE cells.

Additional file 10. Enlargement of Fig. 1d.

\section{Abbreviations}

CDNA: complementary DNA; DNA: deoxyribonucleic acid; EBOV: Zaire ebolavirus; EBV: Epstein-Barr virus; EVD: Ebola virus disease; IFN: interferon; KEGG: Kyoto Encyclopedia of Genes and Genomes; LRRK2: leucine-rich repeat kinase 2; mRNA: messenger RNA; miRNA: microRNA; NF-kB: nuclear factor kappa-light-chain-enhancer of activated B cells; Nt: nucleotide; RIG-I: retinoic acid-inducible gene I; RNA: ribonucleic acid; RNA-Seq: RNA sequencing; RPE: retinal pigment epithelial.

\section{Acknowledgements}

The authors thank Dr. Renee Smith and Ms. Letitia Pimlott of the Flinders Genomics Facility, and Mr. Mark van der Hoek of the South Australian Health \& Medical Research Institute David Gunn Genomics Facility for next-generation sequencing services. The authors also thank Ms. Janet Matthews for bibliographic and other administrative support in the preparation of this manuscript.

\section{Authors' contributions}

GFO, AO, BA, MZM, GAM and JRS conceived the study; GFO, AO, SM, MZM and GAM generated and analyzed experimental data; GO and JRS drafted the manuscript; BA, MZM and GAM provided critical review of the manuscript. All authors read and approved the final manuscript.

\section{Funding}

This work was supported by: Australian Research Council (JRS: FT130101648); National Health \& Medical Research Council Australia (GFO: PGS1150282); Flinders University Faculty of Medicine, Nursing and Health Sciences (JRS); and Avant Doctor-in-Training Scholarship (GFO). The funders had no role in study design, in data collection, analysis and interpretation, or in writing the manuscript.

\section{Availability of data and materials}

All data generated or analysed during this study are included in this published article and its supplementary information files, with the exception of raw data files, which have been lodged in the Gene Expression Omnibus (GEO) of the National Centre for Biotechnology Information (NCBI) as GSE136985.

\section{Ethics approval and consent to participate}

This research involved the use of a commercially available cell line. It did not involve human participants, or the collection of human data or human tissue, and it did not involve animals. Therefore this research was not subject to ethics approval and consent to participate.

\section{Consent for publication}

Not applicable.

\section{Competing interests}

The authors declare that they have no competing interests.

\section{Author details}

${ }^{1}$ Flinders University College of Medicine and Public Health, Flinders Medical Centre Room 4E-431, Flinders Drive, Bedford Park, SA 5042, Australia. ${ }^{2}$ Health and Biosecurity, Commonwealth Scientific and Industrial Research Organisation, 5 Portarlington Rd, Newcomb, VIC 3219, Australia.

Received: 5 August 2019 Accepted: 19 September 2019

Published online: 01 October 2019

\section{References}

1. Mattia JG, Vandy MJ, Chang JC, Platt DE, Dierberg K, Bausch DG, et al. Early clinical sequelae of Ebola virus disease in Sierra Leone: a crosssectional study. Lancet Infect Dis. 2016;16(3):331-8.

2. Tiffany A, Vetter P, Mattia J, Dayer JA, Bartsch M, Kasztura M, et al. Ebola virus disease complications as experienced by survivors in Sierra Leone. Clin Infect Dis. 2016;62(11):1360-6.

3. Shantha JG, Crozier I, Hayek BR, Bruce BB, Gargu C, Brown J, et al. Ophthalmic manifestations and causes of vision impairment in Ebola virus disease survivors in Monrovia, Liberia. Ophthalmology. 2017;124(2):170-7.

4. Varkey JB, Shantha JG, Crozier I, Kraft CS, Lyon GM, Mehta AK, et al. Persistence of Ebola virus in ocular fluid during convalescence [Erratum appears in N Engl J Med. 2015;372(25):2469; PMID: 26030721]. New Engl J Med. 2015;372(25):2423-7.

5. Smith JR, Todd S, Ashander LM, Charitou T, Ma Y, Yeh S, et al. Retinal pigment epithelial cells are a potential reservoir for Ebola virus in the human eye. TransI Vis Sci Technol. 2017;6(4):12.

6. Drury RE, O'Connor D, Pollard AJ. The clinical application of microRNAs in infectious disease. Front Immunol. 2017;8:1182.

7. Dunn KC, Aotaki-Keen AE, Putkey FR, Hjelmeland LM. ARPE-19, a human retinal pigment epithelial cell line with differentiated properties. Exp Eye Res. 1996;62(2):155-69.

8. Martin M. Cutadapt removes adapter sequences from high-throughput sequencing reads. EMBnet J. 2011;17(1):10-2.

9. Harrow J, Frankish A, Gonzalez JM, Tapanari E, Diekhans M, Kokocinski F, et al. GENCODE: the reference human genome annotation for The ENCODE Project. Genome Res. 2012;22(9):1760-74.

10. Kozomara A, Griffiths-Jones S. miRBase: annotating high confidence microRNAs using deep sequencing data. Nucleic Acids Res. 2014;42(D1):D68-73. 
11. Anders S, Pyl PT, Huber W. HTSeq-a Python framework to work with highthroughput sequencing data. Bioinformatics. 2015;31(2):166-9.

12. Love Ml, Huber W, Anders S. Moderated estimation of fold change and dispersion for RNA-seq data with DESeq2. Genome Biol. 2014;15(12):550.

13. Duy J, Honko AN, Altamura LA, Bixler SL, Wollen-Roberts S, Wauquier $\mathrm{N}$, et al. Virus-encoded miRNAs in Ebola virus disease. Sci Rep. 2018;8(1):6480.

14. Paraskevopoulou MD, Georgakilas G, Kostoulas N, Vlachos IS, Vergoulis T, Reczko M, et al. DIANA-microT web server v5.0: service integration into miRNA functional analysis workflows. Nucleic Acids Res. 2013;41(W1):W169-73.

15. Reczko M, Maragkakis M, Alexiou P, Grosse I, Hatzigeorgiou AG. Functional microRNA targets in protein coding sequences. Bioinformatics. 2012;28(6):771-6

16. Agarwal V, Bell GW, Nam JW, Bartel DP. Predicting effective microRNA target sites in mammalian mRNAs. Elife. 2015;4:e05005.

17. Wong N, Wang X. miRDB: an online resource for microRNA target prediction and functional annotations. Nucleic Acids Res. 2015;43(D1):D146-52.

18. Xiao F, Zuo Z, Cai G, Kang S, Gao X, Li T. miRecords: an integrated resource for microRNA-target interactions. Nucleic Acids Res. 2009;37(suppl_1):D105-10.

19. Chou CH, Chang NW, Shrestha S, Hsu SD, Lin YL, Lee WH, et al. miRTarBase 2016: updates to the experimentally validated miRNA-target interactions database. Nucleic Acids Res. 2016;44(D1):D239-47.

20. Ashburner M, Ball CA, Blake JA, Botstein D, Butler H, Cherry JM, et al. Gene ontology: tool for the unification of biology. Nat Genet. 2000;25(1):25-9.

21. Shannon P, Markiel A, Ozier O, Baliga NS, Wang JT, Ramage D, et al. Cytoscape: a software environment for integrated models of biomolecular interaction networks. Genome Res. 2003;13(11):2498-504.

22. Bindea G, Mlecnik B, Hackl H, Charoentong P, Tosolini M, Kirilovsky A, et al. ClueGO: a Cytoscape plug-in to decipher functionally grouped gene ontology and pathway annotation networks. Bioinformatics. 2009:25(8):1091-3.

23. Kanehisa M, Goto S. KEGG: kyoto encyclopedia of genes and genomes. Nucleic Acids Res. 2000;28(1):27-30.

24. Bindea G, Galon J, Mlecnik B. CluePedia Cytoscape plugin: pathway insights using integrated experimental and in silico data. Bioinformatics. 2013;29(5):661-3.

25. Szklarczyk D, Franceschini A, Kuhn M, Simonovic M, Roth A, Minguez $P$, et al. The STRING database in 2011: functional interaction networks of proteins, globally integrated and scored. Nucleic Acids Res. 2011;39(suppl_1):D561-8.

26. Shantha JG, Mattia JG, Goba A, Barnes KG, Ebrahim FK, Kraft CS, et al. Ebola virus persistence in ocular tissues and fluids (EVICT) study: reverse transcription-polymerase chain reaction and cataract surgery outcomes of Ebola survivors in Sierra Leone. EBioMedicine. 2018;30:217-24.

27. Forrester JV. Ebola virus and persistent chronic infection: when does replication cease? Ann Transl Med. 2018;6(Suppl 1):S39.

28. Bernier A, Sagan SM. The diverse roles of microRNAs at the host-virus interface. Viruses. 2018;10(8):440.

29. Cramer EM, Shao Y, Wang Y, Yuan Y. miR-190 is upregulated in EpsteinBarr virus type I latency and modulates cellular mRNAs involved in cell survival and viral reactivation. Virology. 2014;464-465:184-95.

30. Cokaric Brdovcak M, Zubkovic A, Jurak I. Herpes simplex virus 1 deregulation of host microRNAs. Non-coding RNA. 2018;4(4):36.

31. Liston A, Papadopoulou AS, Danso-Abeam D, Dooley J. MicroRNA-29 in the adaptive immune system: setting the threshold. Cell Mol Life Sci. 2012;69(21):3533-41.

32. Edwards MR, Liu G, Mire CE, Sureshchandra S, Luthra P, Yen B, et al. Differential regulation of interferon responses by Ebola and Marburg virus VP35 proteins. Cell Rep. 2016;14(7):1632-40.

33. Cinatl J Jr, Margraf S, Vogel JU, Scholz M, Cinatl J, Doerr HW. Human cytomegalovirus circumvents NF-kappa B dependence in retinal pigment epithelial cells. J Immunol. 2001;167(4):1900-8.

34. Baluni M, Ghildiyal S, Singh D, Reddy DH, Kumar R, Dhole TN. Increased serum microRNA-29b expression and bad recovery in Japanese encephalitis virus infected patients; a new component to improve the disease recovery. J Neuroimmunol. 2018;323:56-61.
35. Grimm C, Butz E, Chen CC, Wahl-Schott C, Biel M. From mucolipidosis type IV to Ebola:TRPML and two-pore channels at the crossroads of endo-lysosomal trafficking and disease. Cell Calcium. 2017;67:148-55.

36. Pleet ML, DeMarino C, Stonier SW, Dye JM, Jacobson S, Aman MJ, et al. Extracellular vesicles and Ebola virus: a new mechanism of immune evasion. Viruses. 2019;11(5):410.

37. Henry AG, Aghamohammadzadeh S, Samaroo H, Chen Y, Mou K, Needle E, et al. Pathogenic LRRK2 mutations, through increased kinase activity, produce enlarged lysosomes with reduced degradative capacity and increase ATP13A2 expression. Hum Mol Genet. 2015;24(21):6013-28.

38. Puccini JM, Marker DF, Fitzgerald T, Barbieri J, Kim CS, Miller-Rhodes $P$, et al. Leucine-rich repeat kinase 2 modulates neuroinflammation and neurotoxicity in models of human immunodeficiency virus 1 -associated neurocognitive disorders. J Neurosci. 2015;35(13):5271-83.

39. Hume A, Muhlberger E. Marburg virus viral protein 35 inhibits protein kinase $R$ activation in a cell type-specific manner. J Infect Dis. 2018;218(suppl_5):S403-8.

40. Zomer A, Vendrig T, Hopmans ES, van Eijndhoven M, Middeldorp JM, Pegtel DM. Exosomes: fit to deliver small RNA. Commun Integr Biol. 2010;3(5):447-50.

41. van der Merwe Y, Steketee MB. Extracellular vesicles: biomarkers, therapeutics, and vehicles in the visual system. Curr Ophthalmol Rep. 2017;5(4):276-82.

42. Wecker T, Hoffmeier K, Plotner A, Gruning BA, Horres R, Backofen R, et al. MicroRNA profiling in aqueous humor of individual human eyes by nextgeneration sequencing. Invest Ophthalmol Vis Sci. 2016;57(4):1706-13.

43. Duy J, Koehler JW, Honko AN, Schoepp RJ, Wauquier N, Gonzalez JP, et al. Circulating microRNA profiles of Ebola virus infection. Sci Rep. 2016;6:24496.

44. Teng Y, Wang Y, Zhang X, Liu W, Fan H, Yao H, et al. Systematic genomewide screening and prediction of microRNAs in EBOV during the 2014 Ebolavirus outbreak. Sci Rep. 2015;5:9912.

45. Liu Y, Sun J, Zhang H, Wang M, Gao GF, Li X. Ebola virus encodes a miR155 analog to regulate importin-alpha5 expression. Cell Mol Life Sci. 2016:73(19):3733-44.

46. Dahlke C, Maul K, Christalla T, Walz N, Schult P, Stocking C, et al. A microRNA encoded by Kaposi sarcoma-associated herpesvirus promotes B-cell expansion in vivo. PLoS ONE. 2012;7(11):e49435.

47. Liang Y, Ridzon D, Wong L, Chen C. Characterization of microRNA expression profiles in normal human tissues. BMC Genomics. 2007;8:166.

48. Xu S. MicroRNA expression in the eyes and their significance in relation to functions. Prog Retin Eye Res. 2009;28(2):87-116.

49. McArdle AJ, Turkova A, Cunnington AJ. When do co-infections matter? Curr Opin Infect Dis. 2018;31(3):209-15.

50. Gupta A, Swaminathan G, Martin-Garcia J, Navas-Martin S. MicroRNAs, hepatitis C virus, and HCV/HIV-1 co-infection: new insights in pathogenesis and therapy. Viruses. 2012;4(11):2485-513.

\section{Publisher's Note}

Springer Nature remains neutral with regard to jurisdictional claims in published maps and institutional affiliations.

Ready to submit your research? Choose BMC and benefit from:

- fast, convenient online submission

- thorough peer review by experienced researchers in your field

- rapid publication on acceptance

- support for research data, including large and complex data types

- gold Open Access which fosters wider collaboration and increased citations

- maximum visibility for your research: over 100M website views per year

At BMC, research is always in progress.

Learn more biomedcentral.com/submissions 